\title{
CONTEXTUALIZAÇÃO DO CICLO DA VIDA JAVAÉ \\ COMPLEXIDADE E SABEDORIA INY/JAVAÉ
}

Hélio Tekuala Javaé

Professor Alfabetizador

Werehatxiari W. Javaé

Professor Alfabetizador

Ruruca Javaé

Professor Alfabetizador

Valdemir Filho Texibà Javaé

Professor Alfabetizador

\section{RESUMO}

Os estudos aqui apresentados tratam da riqueza da cultura Javaé, como, por exemplo, das pinturas. Segundo os especialistas desse saber existem 12 pinturas tradicionais e mais 12 que foram inventadas, tendo ao todo 24 pinturas. Cada uma dessas pinturas Iny está relacionada aos animais, peixes e alguns objetos naturais como: cabaça, feijão etc. Outros conhecimentos também foram estudados: alimentação tradicional, atividades masculina e feminina, trabalho, parentesco, ou seja, pontos importantes da cultura para educar e alfabetizar as crianças e os jovens.

PALAVRAS-CHAVE: Sábios. Cultura. Trabalho e parentesto.

\section{RYBÈNA KYJAKERE}

Kaa tykyriti rarybekere iny bèdèdỹkỹnana ityhymy tuu rarybekere, maha betehekere, iny kyri tyhy riki 12-myre sõè iny bèdèèry tyhy mahãdu tuu rarybèmyhỹre, tarikisỹ 12-myre ijõ irè riki iny riwinyre ixitawodi, taikỹny butuki 24-myre sõè, tahè iny kyrirèny aõnaõna-ò rakoimyhỹre, iròdu, kutura, aõtxile aõòbo, rati-ò kòmyta bohoò. Tasỹ ijõmy idi tykyritinara, hãkỹna byrèna, hãbu lisina ta hãwyky 
lisina, aõmysỹdỹỹna, tasỹmy rybèna, iribihè uladu mahãdu bèdè rièrymyhỹre, weryrybò ta ijadòma boho.

RYBÊ-WÈRYNA: Bèdèkèry. Bèdèdỹkỹnana. Aõmysỹdỹkỹna ta tasỹmy rybèna.

\section{PINTURAS CORPORAIS INY (JAVAÉ)}

A pesquisa foi feita com os mais velhos e algumas pessoas que têm habilidade de pintar como Sr. Dorivaldo Harhesi Javaé, Edivaldo Ijarwie Javaé, Derivaldo Kyriwana Javaé, segundo eles existem 12 pinturas e mais 12 que foram inventadas, tendo ao todo 24 pinturas, falavam que cada uma dessas pinturas Iny está relacionada aos animais, peixes e alguns objetos naturais como: cabaça, feijão, chité etc.

Disseram que jovens estão com dificuldade de pintar, então cabe aos professores indígenas praticar na sala, ou fora da escola. No dia 12 de abril a 15 de maio de 2014 foi realizada oficina de pinturas iny, onde professores indígenas falaram sobre a importância e valorização das pinturas iny, as séries que foram realizadas juntos com professores de $5^{\circ}$ ano a $3^{\circ}$ ano do ensino médio, onde eles pintaram uns aos outros.

O objetivo dessa oficina e aulas é para encontrar e praticar as pinturas corporais iny.

\section{ATIVIDADES MASCULINA E FEMININA}

Primeiro trabalho dos Saberes Indígenas na escola Indígena Tainá foi feito através da pesquisa com ancião Waixawala Javaé, que no mês de agosto de 2014 foi realizada entrevista sobre o ciclo da vida do povo (Iny) Javaé. Explicou que desde crianças as atividades masculina e feminina são ensinadas, ou seja, treinado diferente um do outro, porque as atividades masculinas são mais difíceis, como por exemplo: caçar com arco e flecha no mato; e as atividade femininas são mais fáceis, porque é só na casa ou na aldeia, por exemplo: separar murici maduro em cima da esteira. Estes são alguns exemplos de trabalho. 
Portanto o trabalho foi feito de acordo com a explicação do ancião Waixawala Javaé, que menciona "é bom ensinar o nosso conhecimento na escola", pois está sendo muito bom trabalhar o ciclo da vida nas escolas indígenas no Araguaia-Tocantins, bom para professores e alunos e até a comunidade, porque está ajudando o ensino e valorização da própria cultura indígena, fortalecimento e revitalização do conhecimento que por muito tempo foi silenciado Trúbia
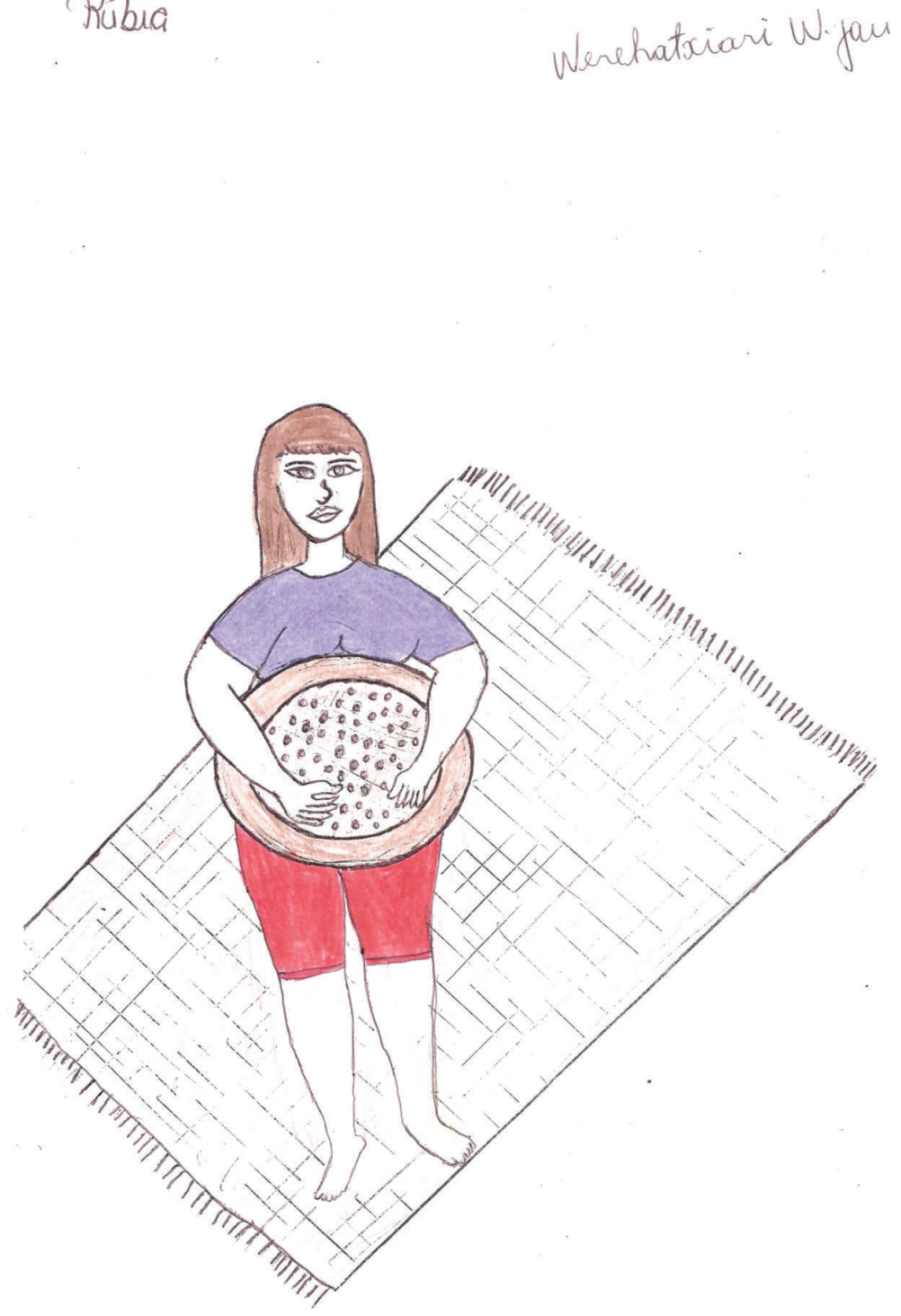
por outro conhecimento.

\section{PREPARAÇÃO DO HOMEM PARA O TRABALHO}

A realização da pesquisa aconteceu no domingo às $14 \mathrm{~h} 30 \mathrm{~min}$ da tarde, iniciei a entrevista com uma anciã chamada Luiza Lawatxiro Javaé, realiza um comentário do preparativo do homem, inicia desde o rapaz quando se casa com uma moça que faz mais a preparação para o trabalho, o avô, o pai ou outra pessoa que prepara recémcasado para permanecer resistente no seu trabalho.

Quando o homem se prepara tem que sofrer muito no seu preparativo, quando o homem inicia a sua preparação não pode comer, depois de realizar a relação sexual e também não pode permanecer sem realizar nada, permanece preguiçoso, por isso o homem tem que se preparar mesmo para o futuro da vida.

O homem tem que fazer o vômito de tarde mais ou menos às $17 \mathrm{~h} 30 \mathrm{~min}$ da tarde e depois faz o jejum uma noite e um dia e meio para permanecer leve e também não permanecer pesado ou preguiçoso ao mesmo tempo faz o risco nas pernas e nos braços e passa pimenta de macaco e outros, quando o homem faz o risco para retirar o sangue contaminado que acontece através da mulher e depois faz passar a pimenta no ânus e dói muito, mas o homem tem que permanecer dentro da água somente uma noite para permanecer forte e resistente.

A preparação do homem serve para todos, não cansa muito e também faz limpeza na garganta para a voz sair saudável, sem perturbação da voz e também serve para fazer a carreira, ele se sente como leve e mata as aves ou animais com a carreira e também serve para as lutas corporais, principalmente para o trabalho, porque através do trabalho as pessoas sustentam suas famílias, por isso os nossos antepassados se prepararam muito, as novas gerações estão deixando a sua cultura tradicional nenhum fazia no tempo passado, por causa disso as novas gerações permanecem perdidas e também ficam pesados ou preguiçosos e comem muito e ficam crescendo a barriga e também não pode beber muita água.

Quando o homem pensa em fazer o vômito tem que procurar o pau que tem casca amarga e cortar um galho para retirar a casca e mistura com a água fica pelo menos 1 hora misturando com a água e 
fica muito amarga para beber, antes de fazer o vômito o homem tem que comer muito, e logo após, o homem tem que beber o remédio para o vômito na beira do rio, por isso acontece sempre na beira do rio, porque muito amarga nem demora um minuto o homem tem vontade de vomitar e sai logo o vômito na beira do rio, as piabas aproveitam esse vômito do homem, hoje em dia nunca fazem as novas gerações como os nossos antepassados, é muito difícil para eles fazerem assim na aldeia.

\section{ESCOLA INDÍGENA IJAWALA}

Mês de junho de 2014, realizei pesquisa com a anciã, a senhora Valdete Warixinoki Javaé, casada na tradição, 45 anos de idade, brasileira, mora na aldeia Barreira Branca desde que nasceu. $\mathrm{O}$ assunto foi sobre a comida tradicional do povo Javaé. Começou falando que hoje as crianças, jovens deixaram de consumir a nossa comida tradicional, hoje eles querem só as comidas dos não indígenas, que são empacotadas, enlatadas, trocaram nosso café da manhã que era caluji pelo café com leite, bolachas, pães, sucos, refrigerantes etc. Falou também que isso não pode acontecer, mas infelizmente é difícil evitar. As comidas que não são tradicionais são um perigo para a sociedade, as comidas citadas em cima trazem diabetes, hipertensão, obesidade etc. Então a preocupação dela é imensa, e o pior é que os pais não negam, eles aceitam o perigo que vem acontecendo na sociedade indígena, poucos pais vem fazendo as roças de toco e outros não fazem, fazem é comprar na cidade, como por exemplo: milho, mandioca, abóbora, batata-doce etc.

Nesse dia, ela resolveu fazer uma palestra na escola para os alunos, e marcamos para o mês de agosto porque logo os alunos estariam de férias e eu no curso de Educação Intercultural - UFG.

No mês de agosto de 2014, convidamos a comunidade, alunos, a anciã Valdete Warixinoki Javaé e a anciã Tereza Ereheru Javaé, viúva, indígena, 89 anos de idade, mais velha da aldeia Barreira Branca. O cacique Valdener Tewadurè Javaé fez abertura falando da importância e da valorização da comida tradicional e incentivou os pais a fazerem a roça de toco. A participação da comunidade foi melhor ainda que todos eles resolveram fazer roça de toco e que irão incentivar os filhos a consumir nossa comida tradicional, 
pessoas que estavam ali deram opiniões e ideias e falaram também da importância da comida tradicional e o perigo que a comida dos nãoindígenas traz para a nossa saúde. Setembro de 2014, realizei pesquisa com o senhor Valdemir Ixerua Javaé, casado, brasileiro, ex-cacique, neto do fundador da aldeia Barreira Branca, iniciou a sua fala com as comidas tradicionais, a importância e que não pode acabar a nossa comida tradicional, falou que antigamente todo mundo fazia a roça e consumiam as comidas tradicionais, e que é muito bom e que ele está pronto para colaborar com seus saberes e conhecimentos que possui. 